\title{
Enhanced allergic sensitisation related to parental smoking
}

R Ronchetti, E Bonci, R Cutrera, G De Castro, L Indinnimeo, F Midulla, G Tancredi, F D Martinez

\begin{abstract}
The objective of this study was to assess the role of parental smoking in changes, after a four year interval (1983-7), in the prevalence and severity of the atopic state in 166 preadolescent children. Allergy skin prick tests were related to parental smoking habits and their changes during this same interval.

The total number of cigarettes smoked by parents decreased in 56 families while it increased in only 16. Boys had significantly more persistently positive skin tests and changed more frequently from negative to positive. The skin test index did not show significant changes in girls. This index did not change in children of persistent non-smokers or those starting to smoke during this period, while it increased among sons of those that quit smoking and of persistent smokers. This was not only due to those boys who became skin test positive during follow up. When analysis was restricted to 14 boys who had been skin test positive in 1983 and whose parents were persistent smokers, the index increased in eight, remained unchanged in four, and decreased in only two.

This report supports the hypothesis that parental smoking is a factor that, together with specific allergenic exposure, may enhance allergic sensitisation in children.
\end{abstract}

A significant association has been described between the prevalence of atopy in children (as assessed by skin prick tests to the most frequent allergens) and the smoking habits of their parents. ${ }^{12}$ This has stimulated new interest in the study of the environmental factors that may enhance atopic expression in predisposed subjects.

Recently a very high correlation has been reported between the incidence of asthma and markers of the atopic state in a large general population sample. ${ }^{3}$ If asthma is associated with allergic sensitisation, ${ }^{3}$ then avoidance of factors predisposing to atopy during childhood may help prevent asthma and chronic airflow limitation later in life.

When we studied a random sample of 166 children aged 9 years, we showed that the prevalence of atopy was significantly higher in the sons of smoking parents than in the sons of non-smoking parents. We also showed, again in boys, that a prick skin test index, calculated from the combined diameters of the weals elicited by the allergens, was correlated with the total number of cigarettes smoked by their parents. We hypothesised that parental smok- ing, by increasing the risk of atopy, may increase the risk of asthma, particularly in their sons. ${ }^{2}$

Little is known about longitudinal changes occurring in skin prick test reactivity during the preadolescent years. Barbee et al reported that, out of 70 subjects aged $6-14$ years, $15(21 \cdot 4 \%)$ had converted from initial negative to positive after a mean of $8 \cdot 1$ years of follow up, while 27 $(38.6 \%)$ remained consistently positive, and 28 $(40 \%)$ remained consistently negative. No subject became skin test negative during this age interval. ${ }^{4}$ These investigators also reported that, paradoxically, total IgE concentrations decreased both in consistent atopic and consistent non-atopic subjects in this same age interval. ${ }^{5}$ Factors other than the direct genetic control of IgE concentrations may play a significant part in atopic sensitisation during this crucial period of life.

The objective of this present study was to assess the role of parental smoking in changes of prevalence and severity of the atopic state in children originally enrolled at the age of 9 years. For this purpose we recalled, after a four year interval, the group of 166 subjects in whom these relationships had already been studied in $1983 .^{2}$ Allergy skin prick tests were repeated and results were related to parental smoking habits during this same interval.

\section{Subjects and methods}

Between September and November 1987 the families of all children in three Italian towns in the Viterbo province (Ronciglione, Caprarola, and Carbognano) who were previously studied at the age of 9 years in 1983, were contacted through their junior high school. Eight families had moved to other towns or could not be found. Informed consent was obtained from 142 (72 boys and 70 girls) of the remaining 158 families, a participation rate of $85.5 \%$. There were no significant differences in health status, prevalence of positive skin tests, or parental smoking habits in 1983 between participants and non-participants in the longitudinal study.

A questionnaire, identical to that used in the previous survey, was administered to one parent. Questions on possible changes in smoking habits of each parent were added. To assess the importance of these changes, households were classified into four groups: (i) those in which there was at least one smoking parent both in 1983 and in 1987 ('persistent smokers'); (ii) those in which both parents were non-smokers, both in 1983 and in 1987 ('persistent nonsmokers'); (iii) those in which at least one 
parent smoked in 1983 and both parents were non-smokers in 1987 ('quitters'); and (iv) those in which both parents were non-smokers in 1983 and at least one parent was a smoker in 1987 ('starters'). As no difference was found in this sample between the effects of paternal and maternal cigarette smoking on skin test reactivity and bronchial responsiveness in the 1983 survey, no effort was made to differentiate these effects during follow up. ${ }^{2}$

Independently from this questionnaire, each child was interviewed privately by a physician regarding his/her cigarette smoking habits, after assuring the child of the confidential character of the interview. Specifically, children were asked: 'Have you ever tried to smoke cigarettes?'. If they answered affirmatively, they were asked if this had happened 'once or twice', 'seldom', or 'at least once a week'. An additional question asked them to specify the number of cigarettes smoked per week or day.

Allergy skin tests were performed using standard skin prick test methods. Extracts used were the same as those applied in our previous survey, namely house dust mites, Alternaria tenuis (fungus), Aspergillus fumigatus (fungus), Poa pratensis (grass), Artemisia vulgaris (compositae), Parietaria officinalis (urticaceae), Olea europea (olive), milk albumin, egg albumin, and cat dander. These represent the most prevalent allergens in central Italy. Operators were unaware of the results of the skin prick tests in the previous survey. The diameters of the weals elicited by the allergens (minus the diameter produced by the control solution) were summed and a skin test index was created with the following classes: class $0=0 \mathrm{~mm}$, class $1=$ 1-2 mm, class $2=3-4 \mathrm{~mm}$, class $3=5-8 \mathrm{~mm}$, class $4=9-16 \mathrm{~mm}$, and class $5=>16 \mathrm{~mm}$.

In addition, four categories of subjects were described by comparing the results of their skin

Table 1 Prevalence of smoking among parents in 1983 and in 1987. Results are number (\%)

\begin{tabular}{llllll}
\hline Survey & $\begin{array}{l}\text { Both parents } \\
\text { non-smokers }\end{array}$ & $\begin{array}{l}\text { Father } \\
\text { smokes only }\end{array}$ & $\begin{array}{l}\text { Mother } \\
\text { smokes only }\end{array}$ & $\begin{array}{l}\text { Both parents } \\
\text { smokers }\end{array}$ & Total \\
\hline 1983 & $39(27)$ & $55(39)$ & $13(9)$ & $35(25)$ & $142(100)$ \\
1987 & $53(37)$ & $51(36)$ & $12(9)$ & $26(18)$ & $142(100)$ \\
\hline
\end{tabular}

Table 2 Changes of skin prick test reactivity between 1983 and 1987 by sex. Results are number (\%)

\begin{tabular}{|c|c|c|c|c|c|}
\hline & \multicolumn{4}{|l|}{ Skin tests } & \multirow[t]{2}{*}{ Total } \\
\hline & $\begin{array}{l}\text { Persistently } \\
\text { positive }\end{array}$ & $\begin{array}{l}\text { Changed from } \\
+ \text { to }-\end{array}$ & $\begin{array}{l}\text { Changed from } \\
- \text { to }+\end{array}$ & $\begin{array}{l}\text { Persistently } \\
\text { negative }\end{array}$ & \\
\hline $\begin{array}{l}\text { Boys } \\
\text { Girls }\end{array}$ & $\begin{array}{r}19(26) \\
9(13)\end{array}$ & $\begin{array}{l}3(4) \\
4(6)\end{array}$ & $\begin{array}{r}12(17) \\
2(3)\end{array}$ & $\begin{array}{l}38(53) \\
55(78)\end{array}$ & $\begin{array}{l}72 \\
70\end{array}$ \\
\hline Total & 28 & 7 & 14 & 93 & 142 \\
\hline
\end{tabular}

prick test performed in 1983 and in 1987: persistently positive, persistently negative, conversion from negative to positive, and conversion from positive to negative.

Fisher's exact test, $\chi^{2}$ test, Wilcoxon's signed ranks test, and Kruskal-Wallis non-parametric analysis of variance were performed using standard Statistical Package for Social Sciences programs. ${ }^{5}$

\section{Results}

Table 1 shows the pevalence of current smokers among mothers and fathers of children included in this study, both for the first survey (1983) and for the present survey (1987). The percentage of non-smoking families increased from $27 \%$ to $37 \%$. In 29 families at least one parent stopped smoking, while in 11 one parent started to smoke; in 102 there was no change in the number of smoking parents during this four year interval $(p=0.009$ by Wilcoxon's signed ranks test). Moreover, the total number of cigarettes smoked by parents decreased in 56 families while it increased in only $16(p<0.0001)$.

Table 2 shows the numbers and percentages of boys and girls among subjects whose skin tests were persistently positive, persistently negative, changed from positive to negative, or changed from negative to positive. Boys were significantly more persistently positive (odds ratio $=3 \cdot 1, p=0.03,95 \%$ confidence interval (CI) $1 \cdot 2$ to $8 \cdot 1$ ) and changed more frequently from negative to positive (odds ratio $=8 \cdot 7$, $\mathrm{p}=0.004,95 \%$ CI $1 \cdot 2$ to $8 \cdot 2$ ). The proportion of skin test positive girls went from $18.6 \%$ in 1983 to $15.8 \%$ in 1987 , while that of skin test positive boys went from $30.6 \%$ to $43 \cdot 1 \%$ during that same interval. As a consequence, mean (SD) skin test index increased significantly in boys from $0.70(1.34)$ to $1.32(1.79)$, with $\mathrm{p}=0.0003$ by Wilcoxon's signed rank rest; but in girls it only increased from $0.46(1.07)$ to $0.59(1.16)$, $p=0.03$. Seven children (three boys, four girls) changed from positive to negative, but their mean skin test index was 1.4 in 1983 - that is, their geometric mean sum of the weal sizes was only between 2 and $4 \mathrm{~mm}$.

Table 3 shows the relationship between parental smoking in 1987 and changes in the results of skin prick tests by gender. In girls, there was no significant relationship between exposure to parental tobacco smoke and the results of skin prick tests performed in 1987 or changes in skin test reactivity between 1983 and 1987. However, 11/34 (32\%) sons of a smoking parent became skin positive during the follow up, compared with $1 / 16(6 \%)$ sons of non-

Table 3 Relationship between parental smoking habits in 1987 and changes in skin prick tests by gender. Results in number (\%)

\begin{tabular}{|c|c|c|c|c|c|}
\hline & \multicolumn{4}{|l|}{ Skin tests } & \multirow[t]{2}{*}{ Total } \\
\hline & $\begin{array}{l}\text { Persistently } \\
\text { positive }\end{array}$ & $\begin{array}{l}\text { Changed from } \\
+ \text { to - }\end{array}$ & $\begin{array}{l}\text { Changed from } \\
- \text { to }+\end{array}$ & $\begin{array}{l}\text { Persistently } \\
\text { negative }\end{array}$ & \\
\hline $\begin{array}{l}\text { Boys: } \\
\text { At least one smoking parent } \\
\text { Both parents non-smokers } \\
\text { Girls: }\end{array}$ & $\begin{array}{r}12(25) \\
7(29)\end{array}$ & $\begin{array}{l}2(4) \\
1(4)\end{array}$ & $\begin{aligned} 11(23) \\
1(4)\end{aligned}$ & $\begin{array}{l}23(48) \\
15(63)\end{array}$ & $\begin{array}{l}48(100) \\
24(100)\end{array}$ \\
\hline $\begin{array}{l}\text { At least one smoking parent } \\
\text { Both parents non-smokers }\end{array}$ & $\begin{array}{l}5(12) \\
4(14)\end{array}$ & $\begin{array}{l}2(5) \\
2(7)\end{array}$ & $\begin{array}{ll}2 & (5) \\
0 & (0)\end{array}$ & $\begin{array}{l}32(78) \\
23(79)\end{array}$ & $\begin{array}{l}41(100) \\
29(100)\end{array}$ \\
\hline
\end{tabular}


smoking parents $(p=0.04$ by Fisher's exact test).

When the households of the boys were classified into four groups (persistent smokers, persistent non-smokers, quitters, and starters, see methods), the parents were more likely to quit smoking between 1983 and 1987 if their sons were skin test positive in 1983. Altogether $60 \%(6 / 10)$ of boys belonging to families where at least one parent smoked in 1983 and none smoked in 1987 were skin test positive in 1983 compared with $7 \%(1 / 14)$ of atopic boys in families of persistent non-smokers $(p=0.007$ by Fisher's exact test). To avoid the confounding effect of this preferential quitting of smoking by families of atopic boys, we repeated the analysis after excluding households in which parental smoking habits had changes during the follow up period. None of 13 skin test negative sons of persistent non-smokers became skin test positive during follow up, while $11 / 33(33 \%)$ sons of persistent smokers became skin test positive during follow up $(\mathrm{p}=0.01$ by Fisher's exact test).

To assess if parental smoking was also associated with an increase in skin test reactivity, the difference between skin test index (STI; expressed in classes, see methods) in 1987 and that in 1983 (delta STI=STI87-STI83) was computed for each subject. In general, mean skin test index did not change in children of persistent non-smoking parents and significantly increased in children whose parents were persistent smokers. This increase was significantly larger in boys than in girls $(p=0.04$ by KruskalWallis one way analysis of variance, ANOVA).

The skin test index did not change or become negative in girls belonging to households where parents were persistent non-smokers, starters, or quitters. Daughters of persistent smokers had higher mean skin test index than daughters of persistent non-smokers (table 4), but this difference did not reach significance $(p=0 \cdot 15$ by ANOVA). Conversely (table 4 ), the skin test index did not change in sons of persistent nonsmokers or starters, while it increased during follow up among sons of quitters and of persistent smokers ( $p=0.03$ by ANOVA). This was not only due to those boys who became skin test positive during follow up; when analysis was restricted to 14 boys who were skin test positive in 1983 and who had parents who were

Table 4 Changes of skin test index during follow up by parental smoking habits and by gender

\begin{tabular}{|c|c|c|c|}
\hline & \multicolumn{3}{|c|}{ Delta skin test index } \\
\hline & Boys & Girls & Total \\
\hline $\begin{array}{l}\text { Persistent non-smokers: } \\
\text { Mean (SD) } \\
\text { No of parents }\end{array}$ & $\begin{array}{l}0.00(0.39) \\
14\end{array}$ & $\begin{array}{l}0.00(0.92) \\
20\end{array}$ & $\begin{array}{l}0.00(0.74) \\
34\end{array}$ \\
\hline $\begin{array}{l}\text { Starters: } \\
\text { Mean (SD) } \\
\text { No of parents }\end{array}$ & $\begin{array}{l}0.00(0.00) \\
3\end{array}$ & $\frac{2}{2}^{-1.00(1.41)}$ & $5^{-0.40(0.89)}$ \\
\hline $\begin{array}{l}\text { Quitters: } \\
\text { Mean (SD) } \\
\text { No of parents }\end{array}$ & $\begin{array}{l}0.50(1 \cdot 58) \\
10\end{array}$ & $9^{-0 \cdot 11(0 \cdot 78)}$ & $\begin{array}{l}0 \cdot 21(1 \cdot 27) \\
19\end{array}$ \\
\hline $\begin{array}{l}\text { Persistent smokers: } \\
\text { Mean (SD) } \\
\text { No of parents }\end{array}$ & $\begin{array}{l}0.87(1 \cdot 36)^{*} \\
45\end{array}$ & $\begin{array}{l}0.30(0.95) \\
39\end{array}$ & $\begin{array}{l}0.61(1 \cdot 21)^{* *} \\
84\end{array}$ \\
\hline
\end{tabular}

${ }^{*} \mathrm{p}=0.03$ when compared with male children of persistent non-smokers.

${ }^{* *} \mathrm{p}=0.005$ when compared with children of persistent non-smokers.

Delta skin test index $($ STI $)=$ STI in 1987 minus STI in 1983. persistent smokers, the skin test index increased in eight, remained unchanged in four, and decreased only in two $(p=0.0004$ when compared with sons of non-smoking parents).

Forty six children (32\%) answered affirmatively to the question 'Have you ever tried to smoke cigarettes?' When asked more detail about these experiences, however, most $(n=31$, $22 \%$ ) affirmed that this had happened only 'once or twice', while eight $(6 \%)$ said they had experienced smoking 'seldom', and seven (5\%) acknowledged smoking at least one cigarette a week. Only two children acknowledged smoking one cigarette a day. In this sample, these first experiences with cigarette smoking were not significantly more frequent in children of smoking parents, and the 15 children who smoked 'seldom' or 'at least one cigarette a week' did not as a group have more smoking parents than children who said they had never tried to smoke cigarettes. There was no significant effect of active smoking on prevalence of (or changes in) skin test reactivity. Exclusion of the above mentioned 15 children from the analyses did not change the results.

\section{Discussion}

The main finding of this longitudinal study is that, between the ages of 9 and 13 years, skin test reactivity to common aeroallergens increases significantly both in frequency and intensity in children, especially in boys, of smoking parents, while it remains unchanged in children of nonsmoking parents. If we tested boys and girls separately we found no significant effect of parental smoking upon skin test reactivity in girls. These findings are in agreement with our previous report ${ }^{2}$ of an increased prevalence of skin test reactivity to the same aeroallergens in boys but not in girls-in a study of this same population sample at the age of 9 years.

It has long been known that atopy runs in families and that this is likely to be due to a genetic predisposition. ${ }^{6-9}$ Recent studies have been implied that atopy has a dominant inheritance pattern and that the gene locus is in chromosome $11 .{ }^{10}$ However, many environmental factors are known to modulate the phenotypical expression of this allergic predisposition. In children of atopic parents, for example, the development of allergy has been temporally associated with the incidence of viral infections. ${ }^{11}$

Active smoking is known to increase the incidence of allergic sensitisation to occupational exposures in otherwise non-atopic subjects. Zetterstrom et al showed that total IgE concentrations increased significantly in rats exposed to tobacco smoke. ${ }^{12}$ They also reported that ovalbumin specific IgE increased significantly in smoke exposed rats when ovalbumin was administered by aerosol but not when rats were immunised against this protein by a subcutaneous route.

This present report supports the hypothesis that parental smoking is a factor that, in conjunction with specific allergenic exposure, may enhance allergic sensitisation in children. Some inaccuracy may be introduced by the self 
reported questionnaire in which each subject has to establish carefully how many cigarettes he smokes. However, our data compare two successive studies in which the same parameters are operating.

It is unlikely that the reported results may be due to other factors. The study subjects belong to a stable rural population on the outskirts of Rome and among whom immigration and emigration are rare. Social status was not significantly different between parents who were smokers or non-smokers, or between persistent smokers, quitters, starters, and 'never smokers', and it is thus not likely to explain our results. It could be argued that active smoking may be more frequent in the sons of smoking parents in this age group and that this could explain our findings. However, we asked children confidentially about their smoking habits and there was no relationship between the responses to this questionnaire and changes in skin test reactivity. In addition, we had previously reported similar gender specificity in the effect of parental smoking when these children were 9 years old, ${ }^{2}$ an age at which it is unlikely that children in our social setting could have started smoking cigarettes. Finally, Burrows et al reported that non-atopic subjects tended to smoke cigarettes more often than atopic subjects, while the latter tended not to start smoking and to give it up if they did begin. ${ }^{13}$ In other words, current smokers had lower atopy rates than ex-smokers and never smokers. ${ }^{13}$ This is opposite to our finding that sons of smoking parents tended to have higher skin test reactivity than sons of non-smoking parents.

No study has been reported that relates changes in skin test reactivity in children to parental smoking habits, and only one has dealt with the issue of longitudinal changes in skin test reactivity in children. Barbee et al reported that skin test reactivity increased significantly both in boys and girls between 6 and 14 and only reached a peak between 20 and 45 years of age. ${ }^{4}$ Our studies would suggest, however, that skin test reactivity is stable between 9 and 13 years of age in girls and in the sons of nonsmoking parents. In these groups, very few skin test positive subjects became skin test negative, and in those who did, the size of the initial weal was small (geometric mean of $<2 \mathrm{~mm}$ ) and perhaps clinically irrelevant. ${ }^{5}$ In these same groups, very few subjects became skin test positive (see table 3). The situation was very different, however, for the sons of smoking parents. Almost one in four of these children became skin test positive during follow up. Barbee et al did not report on the influence of parental smoking or other environmental stimuli on their subjects, and it is thus not possible to compare their findings with ours. ${ }^{4}$

The mechanism by which environmental tobacco smoke enhances sensitisation to aeroallergens is unknown. The studies by Zetterstrom et al in rats suggest that a direct contact between the allergen and the bronchial mucosa is necessary for this increased sensitisation to occur. ${ }^{12}$ This would support the hypothesis that a disruption of the bronchial epithelium by tobacco smoke with increased permeability to antigens may be involved. ${ }^{14}$ It is also possible, however, that the disruption of the epithelium seen in animal models of tobacco smoke inhalation may be the consequence of an inflammatory process occurring in the mucosa, which may also alter the mechanisms by which the aeroallergens are handled and presented to immunocompetent cells in the lung. Active cigarette smoke has also been found to be associated with changes in $T$ lymphocyte function ${ }^{15}$ and it is possible that these changes may alter the complex immunological mechanisms involved in the regulation of IgE production. ${ }^{16}$ Experimental studies are needed to determine the relative importance of these possible mechanisms in determining an increase in allergy skin test reactivity in children of smoking parents.

As in our previous reports, we found that the association between parental smoking and allergy skin test reactivity was much more evident in boys. ${ }^{2}{ }^{17}$ We also found that boys were twice as likely to be skin test positive than girls; this was independent of parental smoking habits (table 3). One possible explanation is that our data cover a small segment of life span in which a difference in age of atopic maturation could cause differences between sexes similar to those we have found. Otherwise, as the gender distribution of atopy does not seem to be directly determined by heredity, ${ }^{18}$ environmental factors may play a significant part in determining the difference in prevalence of atopy between genders. Boys may be more susceptible to environmental noxious stimuli and thus more prone to become sensitised to aeroallergens when their parents smoke.

A significantly higher proportion of smoking parents whose sons were skin test positive in 1983 stopped smoking between 1983 and 1987 when compared with parents of skin test negative children. This was probably due to the fact that we considered it unethical not to inform parents of the results of our previous study and these results may have induced some parents of atopic children to quit smoking. ${ }^{2}$ It is also possible that some of these parents who quitted smoking may have been atopic themselves and thus may have been more likely both to quit smoking ${ }^{13}$ and to have children predisposed to develop skin test reactivity. This may explain at least in part the increase in skin test index among sons of quitters (see table 4). An alternative explanation is also possible, however; early exposure (at or before the age of 9) to cigarette smoke may be more important than that occurring between 9 and 13 years in determining allergic sensitisation. Longitudinal studies including parental skin test reactivity are necessary to elucidate this issue. This study was supported in part by grants from Progetto natale, Consiglio Nazioanale delle Ricerche.

Weiss ST, Tager IB, Munoz A, Speizer FE. The relationship of respiratory infections in early childhood to the occurrence of respiratory infections in early childhood to the occurrence of increased levels of bronchial respon

2 Martinez FD, Antognoni G, Macri F, et al. Parental Martinez FD, Antognoni G, Macri F, et al. Parenta smoking enhances bronchial responsiveness in ni.
children. Am Rev Respir Dis 1988;138:518-23.

3 Burrows B, Martinez FD, Halonen M, Barbee RA, Cline MG. Association of asthma with serum IgE levels and skin test reactivity to allergens. $N$ Engl $\mathcal{f}$ Med 1989;320:271-7. 
4 Barbee RA, Kaltenborn W, Lebowitz MD, Burrows B. A longitudinal change in allergen skin test reactivity in a 1987;79:16-24.

5 Cline MG, Burrows B. Distribution of allergy in a population sample residing in Tucson, Arizona. Thorax 1989;44: sample

6 Norusis MJ. SPSS PC+ . Advanced statistics. 1st Ed. Chicago: SPSS, 1986.

7 Edfors-Lubs ML. Allergy in 7000 twin pairs Acta Allergologica 1971;26:249-85.

8 Schwartz M. Heredity in bronchial asthma. Acta Allergologica 1952;5 suppl 2 .

9 Marsh DG. Allergens and the genetics of allergy. In: Sela M, ed. The antigens. New York: Academic Press, 1975:271.

10 Cookson WOCM, Sharp PA, Faux JA, Hopkin JM. Linkage between immunoglobulin $E$ responses underlying asthma and rhinitis and chromosome 1lq. Lancet 1989;ii:1292-5.

11 Frick OL, German OF, Mills J. Development of allergy in children. I. Association with virus infections. $f$ Allergy Clin Immunol 1979;63:228-41.

12 Zetterstrom O, Osterman K, Machado L, Johansson SGO.
Another smoking hazard: raised serum IgE concentration and increased risk of occupational allergy. BMF 1981;283: 1215-7.

13 Burrows B, Lebowitz MD, Barbee RA. Respiratory disorders and allergy skin test reactions. Ann Intern Med 1976;84: and 9 .

14 Witten ML, Lemen RJ, Quan SF, et al. Acute cigarette smoke exposure increases alveolar permeability in rabbits. smoke exposure increases alveolar perm

15 Holt PG. Immune and inflammatory function in cigarette smokers. Thorax 1987;42:241-9.

16 Romagnani S, Del Prete GF, Maggi E, Ricci M. Activation through CD3 molecule leads a number of human $T$ cell clones to induce IgE synthesis in vitro by $B$ cells from allergic and non-allergic individuals. $\mathcal{F}$ Immunol 1987;138: allergic an

17 Ronchetti R, Martinez FD, Macri F, et al. Increased serum immunoglobulin (IgE) and increased prevalence of eosinophilia in 9 years old children of smoking parents. $\mathcal{F}$ Allergy Clin Immunol 1990;86:400-7.

18 Sibbald B. Genetic basic of sex differences in the prevalence of asthma. $\mathrm{Br} \mathcal{F}$ Dis Chest 1980;74:93-4.

\section{Human herpesvirus-6}

Unless another one has been discovered fairly recently, there are six known human herpesviruses: herpes simplex viruses 1 and 2, cytomegalovirus, varicella zoster virus, Epstein-Barr virus, and human herpesvirus-6 (HHV-6). The latter was identified as the cause of exanthem subitum (roseola infantum) by Japanese workers in $1988 .^{1}$ Infection with HHV-6 is almost universal in young children and between 80 and $100 \%$ of young adults around the world are seropositive, but antibody titres decline after the age of $40 .^{2}$ A very high percentage of adults (more than $85 \%$ in this Californian series ${ }^{2}$ ) shed the virus in saliva and this is the presumed vehicle of infection. Exanthem subitum is, of course, usually benign but infant fatalities have been described, in Japan from fulminant hepatitis ${ }^{3}$ and in China from haemophagocytic syndrome. ${ }^{4}$

A recent report, again from Japan, gives details of the virological findings in 89 infants with exanthem subitum (Yoshizo Asano and colleagues, Fournal of Pediatrics 1991;118:891-5). They showed that children who had prolonged fever (four days or more) had significantly greater viraemia than those with a short fever (three days or less).

For a long time it has been suggested that exanthem subitum might be an important cause of febrile convulsions. Now that the virus is identified we can presumably look forward to early clarification of this relationship.

The Japanese have contributed much to modern medicine. A history of the contribution would be well worth reading.

ARCHIVIST

Yamanishi K, Okuno T, Shiraki K, et al. Identification of human herpesvirus-6 as a causal agent in exanthem subitum. Lancet 1988;i:1065-7.

2 Levy JA, Ferro F, Greenspan D, Lennette ET. Frequent isolation of human herpesvirus-6 from saliva and high seroprevalence of the virus in the population Lancet 1990;335:1047-50.

3 Asano Y, Yoshikawa T, Suga S, et al. Fatal fulminant hepatitis in an infant with human herpesvirus-6 infection. Lancet 1990;335:862-3:

4 Huang L-M, Lee C-Y, Lin K-H, et al. Human herpesvirus-6 associated with fatal haemophagocytic syndrome. Lancet 1990;336:60-1. 